\title{
A Validation Study of the Internet-Specific Epistemic Justification Inventory with Norwegian Pre-Service Teachers
}

\begin{abstract}
The purpose of this study was to validate a new inventory designed to measure epistemic beliefs concerning the justification of knowledge claims encountered on the Internet. Confirmatory factor analysis of the scores of 394 pre-service teachers showed that a threefactor model including justification by authority, justification by multiple sources, and personal justification fit the data well. Moreover, latent variable structural equation modeling showed that these three types of justification beliefs differentially predicted aspects of Internet-specific reading motivation and engagement. Taken together, these results provide evidence for the construct validity of the inventory and lay the foundation for further validation work. The theoretical and educational significance of the study is discussed and directions for future research are suggested.
\end{abstract}

\section{Running head}

Internet-specific epistemic justification

\section{Authors}

Ivar Bråten and Christian Brandmo

University of Oslo, Norway

Yvonne Kammerer

Leibniz-Institut für Wissensmedien, Germany 


\section{Corresponding author}

Ivar Bråten, Department of Education, University of Oslo, P.O. Box 1092 Blindern, N-0317

Oslo, Norway. Phone: +47 228552 82, Fax: +47 228542 50, E-mail:

ivar.braten@ped.uio.no

\section{Acknowledgement}

The research reported in this article was funded by grant 237981/H20 from the Research Council of Norway to Ivar Bråten.

\section{Keywords}

Internet-specific epistemic beliefs; justification for knowing; reading motivation and engagement; confirmatory factor analysis; structural equation modeling.

\section{Author bios}

Ivar Bråten is professor of educational psychology at the Faculty of Educational Sciences at the University of Oslo, Norway.

Christian Brandmo is associate professor of educational leadership at the Faculty of

Educational Sciences at the University of Oslo, Norway.

Yvonne Kammerer is research scientist at the Leibniz-Institut für Wissensmedien, Tübingen, Germany. 


\section{Introduction}

The Internet has become an important knowledge resource for academic issues, providing easy access to vast amounts of information from multiple sources. However, because anyone can publish freely on the Internet, online information addressing academic issues can vary considerably in terms of quality. Thus, critical users of the Internet need to justify the knowledge claims they encounter online.

The purpose of this study was to investigate the validity of a new measure designed to capture three types of beliefs concerning the justification of knowledge claims encountered on the Internet. We did this by analyzing the scores of pre-service teachers on the measure by means of confirmatory factor analysis to ascertain its three-dimensional structure. Further, we used latent variable structural equation modeling to test relations between the underlying constructs resulting from the confirmatory factor analysis and aspects of motivation and engagement when reading on the Internet. In this way, we essentially followed the classic procedure for construct validation described by Cronbach and colleagues (Cronbach, 1990; Cronbach \& Meehl, 1955). Prior theoretical and empirical work has addressed people's perceptions of the credibility and usefulness of Internet-based information (e.g., Lankes, 2008; Lucassen, Muilwijk, Noordzij, \& Schraagen, 2013; Sussman \& Siegal, 2003). However, this study is distinguished by its focus on theory and research within personal epistemology, especially concerning beliefs about justification of knowledge claims encountered on the Internet, as a background for the construction and validation of a new instrument. Before we further specify the research questions and hypotheses for our study, we discuss relevant theoretical frameworks and prior empirical work.

\section{1 Theoretical and empirical background}

Beliefs about justification for knowing belong to the realm of personal epistemology, which concerns beliefs laypeople (i.e., non-philosophers) hold about the nature of knowledge 
and the process of knowing (Bråten, 2011; Hofer, 2002). In a landmark review of personal epistemology, Hofer and Pintrich (1997) proposed a four-dimensional framework that included a justification for knowing dimension, which ranged from justification through observation and authority, or on the basis of what feels right, to the use of rules of inquiry and the evaluation and integration of multiple information sources. In addition, their framework included dimensions concerning the certainty, simplicity, and source of knowledge. The certainty dimension ranged from the view that knowledge is absolute and unchanging to the view that knowledge is tentative and evolving, the simplicity dimension ranged from the view that knowledge consists of isolated facts to the view that knowledge consists of complex, integrated concepts, and the source dimension ranged from the view that knowledge is transmitted from external authority to the view that knowledge is actively constructed by the person. During the past two decades, a large amount of empirical work has been framed by Hofer and Pintrich's (1997) conceptualization, indicating that where students fall on these dimensions has implications for their motivation, cognition, and performance in academic settings (for reviews, see Bråten, 2011; Bråten, Strømsø, \& Ferguson, 2016; Hofer \& Bendixen, 2012; Sandoval, Greene, \& Bråten, 2016). Of particular interest in the context of the current investigation are studies that have focused on learning within Internet technologies and, at the same time, used a measure targeting Internet-specific epistemic beliefs.

This line of research was initiated by Bråten, Strømsø, and Samuelstuen (2005), who argued that because the Internet represents a particular type of knowledge resource that allows for new ways of presenting knowledge and new ways of knowing compared to conventionalprint environments, researchers should use epistemic belief measures that target what individuals believe knowledge is like on the Internet and how they come to know on the Internet when studying learning within Internet technologies. Accordingly, these authors designed the 36-item Internet-Specific Epistemological Questionnaire (ISEQ), which was 
based on Hofer and Pintrich's (1997) framework and thus addressed beliefs concerning the certainty, simplicity, and source of Internet-based knowledge, as well as beliefs concerning the justification of knowledge claims encountered on the Internet.

In addition to the original study (Bråten et al., 2005), the ISEQ has been used in a range of published studies during the last decade, with those studies conducted with Norwegian (Strømsø \& Bråten, 2010), German (Kammerer, Amman, \& Gerjets, 2015; Kammerer, Bråten, Gerjets, \& Strømsø, 2013; Kammerer \& Gerjets, 2012), Chinese (Cheng, Liang, \& Tsai, 2013; Chiu, Liang, \& Tsai, 2013, 2016; Chiu, Tsai, \& Liang, 2015; Lee, Chiu, Liang, \& Tsai, 2014), English (Cho, Woodward, \& Li, in press; Knight et al., 2017a, 2017b), Turkish (Karaoglan Yilmaz, \& Cakmak, 2016), and Persian (Karimi, 2014) versions of the instrument. In studies using factor analysis, only those using the Chinese version of ISEQ have provided evidence for the four-dimensional conceptualization on which the measure is based (Chiu et al., 2013, 2016; Lee et al., 2014). However, those factor solutions have retained only three of the original ISEQ items in each of the four dimensions, thus comprising only 12 of the 36 original items. The other studies using factor analysis have either found a broad factor including items written to assess beliefs about the certainty, simplicity, and source of knowledge (termed "general Internet epistemology" by Bråten et al., 2005) together with a justification for knowing factor (Bråten et al., 2005; Kammerer et al., 2013; Knight et al., 2017a), or a factor including items written to assess beliefs about certainty and source of knowledge together with a simplicity of knowledge factor and a justification for knowing factor (Karimi, 2014; Strømsø \& Bråten, 2010). However, none of these two- or three-factor solutions have included more than 18 of the original 36 ISEQ items.

Regarding relationships with other constructs, higher scores on the ISEQ factors including items focusing on the certainty, simplicity, and source of knowledge, which reflect the view that the Internet is a reliable source of certain (i.e., true, accurate) and simple (i.e., 
detailed, factual) knowledge, have been found to predict higher levels of self-reported Internet search and evaluation skills (Bråten et al., 2005; Strøms $\varnothing$ \& Bråten, 2010), self-regulated strategies (Chiu et al., 2013; Strømsø \& Bråten, 2010), and adaptive online help seeking (Bråten et al., 2005; Lee et al., 2014; Strøms $\varnothing ~ \&$ Bråten, 2010), as well as the extent to which learners actually access more objective, reliable web pages during web search (Kammerer et al., 2015; Kammerer \& Gerjets, 2012). However, other studies have suggested that higher scores on a broad factor containing such items may negatively predict critical evaluation of Internet-based sources (Kammerer et al., 2013; Knight et al., 2017a). In studies using the ISEQ, higher scores on the justification for knowing factor, reflecting the view that knowledge claims on the Internet need to be checked against other sources, reason, and prior knowledge, have been found to predict higher levels of self-reported self-regulated strategies (Chiu et al., 2013; Strømsø \& Bråten, 2010) and adaptive online help seeking (Lee et al., 2014), as well as more critical evaluation of websites (Knight et al., 2017a) and avoidance of one-sidedness and construction of a balanced representation when encountering conflicting claims across multiple websites (Kammerer et al., 2013). Kammerer et al. (2015) distinguished between Internet-specific beliefs concerning justification by multiple sources and beliefs concerning personal justification, using two original ISEQ items to assess each dimension. Interestingly, these authors found that the more individuals believed that Internetbased knowledge claims need to be compared and corroborated across multiple sources, the more time they spent on reliable websites during a web search on a controversial medical issue. Conversely, the more individuals believed that knowledge claims should be evaluated in relation to their own knowledge and logical thinking, the more they focused on less reliable, commercial websites.

Although important work recently has been done in the area of Internet-specific epistemic beliefs, indicating that such beliefs matter when learning within Internet 
technologies, problematic aspects of this work concern not only measurement but also theoretical grounding. Besides the fact that scores on the ISEQ have not consistently represented its hypothesized four-factor structure, that few of the original ISEQ items have been included in the resulting factors, and that empirical findings are somewhat contradictory, further theoretical development within personal epistemology has not been taken into consideration. In particular, this concerns the assumption that beliefs about justification for knowing cannot be captured by a single dimension but, rather, should be differentiated into several dimensions in accordance with how philosophers identify a number of different sources involved in justifying knowledge claims (Chinn, Buckland, \& Samarapungavan, 2011; Greene, Azevedo, \& Torney-Purta, 2008). Such a multidimensional conceptualization of beliefs about justification for knowing has also gained empirical support, with separate dimensions concerning justification by authority, justification by multiple sources, and personal justification emerging from recent quantitative and qualitative work addressing the dimensionality of personal epistemology (Ferguson, Bråten, \& Strøms $\varnothing, 2012$; Ferguson, Bråten Strømsø, \& Anmarkrud, 2013; Greene, Torney-Purta, \& Azevedo, 2010).

Moreover, a number of recent empirical studies have validated this trichotomous framework by linking students' justification for knowing to their motivation, cognition, and performance (Braasch, Bråten, Britt, Steffens, \& Strømsø, 2014; Brandmo \& Bråten, 2018; Bråten, Anmarkrud, Brandmo, \& Strømsø, 2014; Bråten \& Ferguson, 2014; Bråten, Ferguson, Anmarkrud, Strømsø, \& Brandmo, 2014; Bråten, Ferguson, Strømsø, \& Anmarkrud, 2013; Bråten, Ferguson, Strøms $\varnothing$, \& Anmarkrud, 2014; Ferguson \& Bråten, 2013; Kendeou, Braasch, \& Bråten, 2016; Strøms ø, Bråten, Anmarkrud, \& Ferguson, 2016; Trevors, Kendeou, Bråten, \& Braasch, 2017). Quite consistently, these studies have shown that justification by multiple sources is positively related to students' motivation, cognition, and performance, whereas personal justification is negatively related to their motivation, cognition, and 
performance. Of note is, however, that in these studies, personal justification has been measured in terms of justification by personal views or opinions rather than by activation of prior knowledge and reasoning. With respect to justification by authority, some studies have found this dimension to be unrelated to students' performance (Brandmo \& Bråten, 2018; Bråten et al., 2013; Bråten, Ferguson, Strømsø, et al., 2014; Kendeou et al., 2016), while other studies have found it to be positively related to performance for certain tasks and cultural groups (Braasch et al., 2014; Strømsø et al., 2016).

Importantly, research conducted within the trichotomous justification belief framework has targeted beliefs about a particular content domain whereas research on Internet-specific epistemic beliefs using the ISEQ has targeted beliefs about Internet-based knowledge and knowing in relation to students' course work or in general (Strømsø \& Kammerer, 2016). Thus, beyond addressing the Internet as a particular domain in the epistemological sense (Bråten et al., 2005), recent theory and research highlighting the domain-specific and topic-specific nature of epistemic beliefs have so far not been taken into consideration when investigating Internet-specific epistemic beliefs (Bråten, Gil, Strøms $\varnothing, \&$ Vidal-Abarca, 2009; Muis, Bendixen, \& Haerle, 2006; Sandoval, Greene, \& Bråten, 2016).

\subsection{The present study}

Given this theoretical and empirical background, we set out to validate an Internetspecific epistemic belief measure designed to assess beliefs about justification for knowing on the Internet in relation to a specific content domain. More specifically, we grounded our measure in the trichotomous justification belief framework (Ferguson et al., 2012, 2013), addressing justification by authority, justification by multiple sources, and personal justification. In doing this, we tried to bring research in this area in line with recent theoretical and empirical developments within personal epistemology (Mason \& Florit, 2018). Further, in addition to focusing on beliefs about justification for knowing on the Internet, in particular, 
we designed our measure such that it targeted beliefs about justification for knowing in relation to a specific content domain, thus taking the domain-specific nature of epistemic beliefs into consideration (Bråten et al., 2009; Muis et al., 2006; Sandoval et al., 2016). In a sample of Norwegian pre-service teachers, we expected to identify three constructs underlying their scores on this measure when asked about their justification of knowledge claims encountered on the Internet that concerned educational topics, with these constructs corresponding to justification by authority, justification by multiple sources, and personal justification.

To further investigate these three Internet-specific justification constructs, we tested relations between the three types of beliefs and aspects of motivation and engagement when reading about educational topics on the Internet, using latent variable structural equation modeling for this purpose. Following Guthrie and Klauda (2014), we focused on positive as well as negative aspects of motivation (viz., perceived competence and perceived difficulty) and engagement (viz., dedication and avoidance) (see Section 2.2.2 for how we measured these constructs). The model displayed in Figure 1 specifies our hypotheses concerning the relationships between the three types of justification beliefs and these positive and negative forms of motivation and engagement.

[Figure 1 about here]

As can be seen, we expected beliefs about justification by multiple sources to positively predict perceived competence and dedication and negatively predict avoidance. This is in accordance with previous research within the trichotomous framework, which has found positive relations between such beliefs, albeit not targeting Internet-based knowledge, in particular, and student motivation and engagement (see Section 1.1). The reason we did not expect justification by multiple sources to negatively predict perceived difficulty as well, is 
that we considered it likely that many of those oriented towards multiple sources would also realize the complexity of the domain in question.

With respect to personal justification, we expected this construct to positively predict perceived competence and negatively predict perceived difficulty. This is because we, in contrast to previous research on this construct, focused on personal justification in terms of prior knowledge and reasoning rather than own opinion when designing the current measure. Thus, it seems reasonable to expect that those who relied more on their own prior knowledge and reasoning in evaluating knowledge claims also perceived themselves as more competent and considered the content less difficult than did those who relied less on their own prior knowledge and reasoning skills. However, we did not expect personal justification to be uniquely related to the engagement constructs of dedication and avoidance. This is because we considered it likely that justification by multiple sources and personal justification would be positively correlated and that justification by multiple sources would be a better predictor of the engagement constructs than would personal justification.

With respect to justification by authority, inconsistent findings obtained in previous research within the trichotomous framework (see Section 1.1) made it difficult to specify predictive relationships between justification by authority and the motivation and engagement constructs. However, we entertained the possibility that justification by authority might be a unique negative predictor of perceived competence because those relying on external authority when justifying knowledge claims might also perceive themselves as less competent regarding the domain in question.

Finally, regarding correlations, we expected the three constructs concerning justification for knowing to be positively correlated. Thus, students using their own prior knowledge and reasoning in evaluating knowledge claims may also be inclined to corroborate claims and evidence across sources, and those who rely on multiple sources may also be 
concerned about the authoritativeness of the sources they access. Personal justification and justification by authority may be expected to correlate because prior knowledge and reasoning may well be used to evaluate the authoritativeness of the source as well as the content of the claim.

In accordance with Guthrie and Klauda (2014), we expected the two positive motivation and engagement constructs (i.e., perceived competence and dedication) as well as the two negative motivation and engagement constructs (i.e., perceived difficulty and avoidance) to be positively correlated. In addition, we expected that each of the two positive constructs would be negatively correlated with each of the negative constructs (Guthrie \& Klauda, 2014).

\section{Method}

\subsection{Participants}

Participants were 394 pre-service teachers (64\% female) from four teacher education programs in a large city in southeast Norway. In Norway, there are two main tracks of teacher education that include four different programs: a one-year program at postgraduate level that qualifies for teaching in secondary school (grades 8-13) and three five-year master programs that qualify for teaching in primary school (grades 1-7), upper primary and lower secondary school (grades 5-10), and secondary school (grades 8-13), respectively. One-hundred and seventy-five participants attended the one-year postgraduate program, 96 attended the fiveyear master program qualifying for grades 8-13, and 123 attended the five-year master program qualifying for grades 1-7. The first two programs were located at the University of Oslo and the third was located at Oslo University College. Participants ranged in age from 21 to 63 years with an overall mean age of $28.14(S D=5.38)$. The majority of the participants $(83 \%)$ were born in Norway and learned Norwegian as their first language, and the rest were bilingual, most of them raised in Norway, but with parents from different parts of the world. 
With regard to educational background, 27\% had earned 60 ECTS (European Credit Transfer and Accumulation System) credits, $41 \%$ had earned 180 credits (equivalent to a bachelor's degree), $30 \%$ had earned 300 credits (equivalent to a master's degree), and 2\% had completed a Ph.D. None of the participants had studied less than one and a half year at postsecondary level. All participants were studying educational topics at the time of data collection.

Although this was a nonprobability sample whose representativeness of Norwegian preservice teachers may be open to question (cf., Kerlinger \& Lee, 2000), we purposefully selected participants such that they represented different tracks of teacher education and different teacher education programs and institutions, with participants also varying considerably with respect to age and educational background. As such, the sample also was less homogeneous than many other samples used in personal epistemology research (Greene et al., 2008).

\subsection{Materials}

\subsubsection{The Internet-Specific Epistemic Justification Inventory}

To assess participants' Internet-specific epistemic beliefs concerning justification for knowing, we developed the Internet-Specific Epistemic Justification Inventory (ISEJ). The 12-item ISEJ was based on a multidimensional conceptualization of justification for knowing (Ferguson et al., 2012, 2013; Greene et al., 2008, 2010) that includes beliefs concerning justification by authority, justification by multiple sources, and personal justification. All 12 items targeted justification beliefs when using the Internet as a knowledge resource. In this study, we specified the content domain as education; however, the items may easily be adapted to concern other domains and topics. All items of the ISEJ are displayed in Appendix

A.

The four items written to assess justification by authority focused on evaluation of information located on the Internet in light of the competency and expertise of the source 
(sample item: When I read something about an educational topic on the Internet, I evaluate whether this information is written by an expert). The four items written to assess justification by multiple sources concerned evaluation of information found on the Internet by checking several information sources and comparing across websites (sample item: To evaluate whether information I find on the Internet about an educational topic is reliable, I check whether it is consistent with information on other websites). Two of these items were adapted from justification for knowing items included in the ISEQ (Bråten et al., 2005), and one item was adapted from a justification by multiple sources item included in Ferguson et al.'s (2013) Justification for Knowing Questionnaire (JFK-Q). Finally, the four items written to assess personal justification concerned evaluation of information found on the Internet based on prior knowledge and reasoning (sample item: When I find information about an educational topic on the Internet, I evaluate whether this information is consistent with my own understanding of the topic). Two of these items were adapted from justification for knowing items on the ISEQ (Bråten et al., 2005). Participants rated each item included in the ISEJ on a 10-point anchored scale ranging from strongly disagree (1) to strongly agree (10).

\subsubsection{Motivation and engagement measures}

To assess participants' Internet-specific reading motivation and engagement, we adapted items from Guthrie and Klauda's (2014) reading motivation and engagement scales. Specifically, we adapted three items from their perceived competence scale and three items form their perceived difficulty scale to measure both positive and negative aspects of selfreported motivation when reading about educational topics on the Internet. Moreover, we adapted three items from their dedication scale and three items from their avoidance scale to measure both positive and negative aspects of self-reported behavioral engagement. A focus on both positive (i.e., perceived competence and dedication) and negative (i.e., perceived difficulty and avoidance) aspects of motivation and engagement is based on the rationale that 
positive and negative forms cannot be considered simple opposites (Guthrie \& Klauda, 2014). For example, a substantial proportion of readers may perceive themselves as competent and still consider the task difficult, and a substantial proportion of students may display low engagement as well as low avoidance.

The three items used to measure perceived competence focused on the extent to which participants perceived themselves capable of learning from and understanding what they read about educational topics on the Internet (sample item: I figure out the meaning of central academic concepts by reading about educational topics on the Internet). The three items used to measure perceived difficulty concerned the extent to which participants perceived what they read about educational topics on the Internet to be difficult or confusing (sample item: What I read on the Internet about educational topics is far too difficult for me). The three items used to assess dedication focused on the extent to which participants put time, effort, and persistence into reading about educational topics on the Internet (sample item: I spend more time and effort on reading about educational topics on the Internet than other students). Finally, the three items used to measure avoidance concerned the extent to which participants had an aversion towards reading about educational topics on the Internet and therefore expended as little time and effort as possible on this activity (sample item: I read as little as possible about educational topics on the Internet).

Participants rated each of the 12 items on a 10-point anchored scale ranging from strongly disagree (1) to strongly agree (10). All items used to measure participants' selfreported Internet-specific reading motivation and engagement are displayed in Appendix B.

\subsection{Procedure}

Data collection took place during regular lectures in participants' ordinary classrooms, with the measures group administered by the second author and a trained research assistant. Participants were informed that participation in the study was voluntary but only five of those 
present chose not to participate. Participants were not compensated for their participation in any way. All data were treated anonymously and confidentially. Participants completed a demographics survey, followed by the measures of reading motivation and engagement and the Internet-Specific Epistemic Justification Inventory. Approximately 15 minutes were used to complete all the materials.

\subsection{Analytic approach}

To investigate the construct validity of the Internet-Specific Epistemic Justification Inventory, we first performed confirmatory factor analysis (CFA) to test how well the theoretical model (i.e., the trichotomous justification belief framework) fit the data. To evaluate the fit, we used chi-square statistics and fit-indices reported by the Mplus software (Muthén \& Muthén, 2012): the comparative fit index (CFI), the Tucker Lewis fit index (TLI), the root mean square error of approximation (RMSEA), and the standardized root mean square residual (SRMR). After reviewing the literature on cut-off criteria for goodness of fit (Bentler, 1990; Bentler \& Bonett, 1980; Hu \& Bentler, 1998, 1999; Marsh, Hau, \& Wen, 2004; Schermelleh-Engel, Moosbrugger, \& Müller, 2003), and taking the current analytic situation (e.g., model complexity) into consideration, we adopted the following criteria for model evaluation: CFI and TLI $\geq .90, \mathrm{RMSEA} \leq .08$, and $\mathrm{SRMR} \leq .09$ indicate an acceptable fit of the model, while CFI and TLI $\geq .95, \mathrm{RMSEA} \leq .05$, and $\mathrm{SRMR} \leq .06$ indicate a good model fit. In addition to evaluating the overall model fit, we examined the factor loadings (and possible cross-loadings) and the intercorrelations between the factors. In this process, we computed factor determinacy scores (FDS) and two reliability estimates, Cronbach's $\alpha$ and the scale reliability for each latent factor $(\rho)$. FDS is a validity coefficient, specifically a correlation between the estimated factor score and the true factor score that ranges from zero to one and describes how well the factor in question is measured. According to Brown (2015), a factor determinacy score should be at least .80 and preferably above .90 . The reason we 
computed $\rho$ in addition to Cronbach's $\alpha$ is that the latter can under- or overestimate the reliability if assumptions of a tau-equivalent measurement model are violated (e.g., the assumption of equal factor loadings; Graham 2006), whereas the former benefits from the CFA environment and overcomes the weaknesses associated with Cronbach's $\alpha$ (Brown, 2015). Although reliability estimates have to be interpreted in relation to the nature of the phenomenon that is measured, Kline (2005) gave the following general guidelines for their interpretation: estimates above .70 are to be considered adequate, estimates above .80 are very good, and estimates above .90 are excellent.

The second step in our construct validation involved testing hypothesized relations between the latent factors resulting from the CFA of the scores on the Internet-Specific Epistemic Justification Inventory and the Internet-specific reading motivation and engagement constructs. We used structural equation modeling (SEM) in this regard. While providing information about convergent and discriminant validity (Campbell and Fiske, 1959), this approach also controls for the effects of the other epistemic justification constructs when testing relations between each epistemic justification construct and the motivation and engagement constructs. In addition, this approach provides information about overall model fit (see above).

\section{Results}

Initially, we examined all item-level justification variables with respect to distributional properties (see Table 1 for descriptive statistics). None of the items on the Internet-Specific Epistemic Justification Inventory had a skewness or kurtosis above one. We therefore decided to use ordinary maximum likelihood extraction for the CFA.

Next, we specified the three-factor model of justification beliefs, including justification by authority, justification by multiple sources, and personal justification, and performed a CFA by means of Mplus 7.2 (Muthén \& Muthén, 2012). This model fit the data 
well, with $\chi^{2}(51)=142, p<.001 ;$ CFI $=.97 ;$ TLI $=.97 ;$ RMSEA $=.067,90 \%$ CI $[.054-$ $.081]$; SRMR $=.036$. As also displayed in Table 1, all the justification items had sufficient loadings, with loadings ranging from .68 to .93. Further, as can be seen in Table 1, the factor determinacy scores and the reliability estimates were all very good.

[Table 1 about here]

We also performed a CFA of the scores on the 12 items used to measure Internetspecific reading motivation and engagement. All these items were normally distributed, and the hypothesized four factor-structure fit the data well, with $\chi^{2}(48)=88, p<.001 ; \mathrm{CFI}=.98$; $\mathrm{TLI}=.97 ; \mathrm{RMSEA}=.046,90 \% \mathrm{CI}[.030-.061] ; \mathrm{SRMR}=.040$. Further, all items had sufficient loadings, ranging from .61 to .85 , and the factor determinacy scores and the reliability estimates were good (perceived competence: $\operatorname{FDS}=.90, \alpha=.76, \rho=.76$; dedication: $\mathrm{FDS}=.91, \alpha=.76, \rho=.78$; perceived difficulty: $\mathrm{FDS}=.89, \alpha=.79, \rho=.79$; avoidance: $\mathrm{FDS}=.92, \alpha=83, \rho=.83$ ).

[Table 2 about here]

Intercorrelations between all latent variables included in the SEM analysis are displayed in Table 2, together with the means and standard deviations for those variables. When we tested the hypothesized model displayed in Figure 1, the fit indices indicated a properly fitted model, with $\chi^{2}(231)=424, p<.001 ; \mathrm{CFI}=.96 ; \mathrm{TLI}=.96 ; \mathrm{RMSEA}=.046$, 90\% CI [.039 - .053]; SRMR $=.041$. The resulting model is displayed in Figure 2. Taken together, the three justification for knowing constructs explained $10 \%$ of the variance in perceived competence, $6 \%$ of the variance in dedication, $8 \%$ of the variance in perceived difficulty, and $4 \%$ of the variance in avoidance.

[Figure 2 about here]

As expected, justification by multiple sources was a unique positive predictor of perceived competence $(\beta=36, p<.001)$ and dedication $(\beta=.18, p<.05)$, and a unique 
negative predictor of avoidance $(\beta=-.21, p<.001)$. This indicates that participants who believed that information about educational topics encountered on the Internet needs to be corroborated by comparing various sources also perceived themselves as more competent, reportedly put more time, effort, and persistence into reading about such topics on the Internet, and reportedly experienced less aversion in relation to reading about such topics on the Internet. As expected, the path from justification by multiple sources to perceived difficulty was not statistically significant, however. While a large proportion of the participants believing in justification by multiple sources may have considered the task easy, many of those believing in justification by multiple sources presumably also realized the complexity of reading about educational topics on the Internet.

Personal justification, as expected, was a unique negative predictor of perceived difficulty $(\beta=-.23, p<.001)$, indicating that participants who believed in evaluating information about educational topics on the Internet by means of their own prior knowledge and reasoning were also less likely to perceive what they read about such topics on the Internet to be difficult or confusing. Although we also expected that personal justification would be a unique positive predictor of perceived competence, this path was not statistically significant. The statistically non-significant paths from personal justification to the engagement constructs of dedication and avoidance were consistent with our expectations, however.

With regard to justification by authority, only one path from this construct to the motivation and engagement constructs was statistically significant. As expected, this was the path to perceived competence $(\beta=-.17, p<.05)$, which indicates that participants who believed that information about educational topics encountered on the Internet needs to be justified by referring to the competency or expertise of the source, were also less likely to perceive themselves as capable of learning from and understanding what they read about 
educational topics on the Internet. The finding that justification by authority did not uniquely predict the other motivation and engagement constructs seems consistent with previous research on justification by authority conducted within the trichotomous justification belief framework (e.g., Brandmo \& Bråten, 2018).

As expected, the three constructs concerning justification for knowing were positively correlated, with personal justification positively correlated with both justification by multiple sources $(r=.58, p<.001)$ and justification by authority $(r=.56, p<.001)$, and with justification by multiple sources positively correlated with justification by authority $(r=.67, p$ $<.001)$. Most of the correlations between the motivation and engagement constructs were also consistent with our expectations. Thus, perceived competence was positively correlated with dedication $(r=.68, p<.001)$, and perceived difficulty was positively correlated with avoidance $(\beta=.31, p<.001)$. Moreover, both perceived competence $(r=-.65, p<.001)$ and dedication $(r=-.56, p<.001)$ were negatively correlated with avoidance. That both perceived competence $(r=.05, n s)$ and dedication $(r=.10, n s)$ were unrelated to perceived difficulty was not consistent with our expectations, however.

\section{Discussion}

Learning within Internet technologies may represent a greater challenge for students than learning with conventional-print materials (Bråten \& Braasch, 2017; Strøms $\varnothing$ \& Kammerer, 2016). This is because the relaxed parameters for publishing on the Internet require an extraordinary alertness on part of the students, such that they carefully evaluate the claims about academic issues that they encounter on the Internet before they accept them as valid knowledge. Presumably, this can be done by judging the authoritativeness of the source (e.g., the expertise of the author), drawing on prior knowledge and reasoning about the topic in question, and cross-checking various sources for consistency. In the current study, we therefore investigated whether these ways of knowing on the Internet could be adequately 
captured by a new instrument: The Internet-Specific Epistemic Justification Inventory (ISEJ). Given the results of our validation of this instrument, we sincerely believe that this question can be answered in the affirmative. Thus, not only did we confirm that the constructs of justification by authority, personal justification, and justification by multiple sources lay behind participants' scores on the ISEJ, we were also able to demonstrate that these three constructs, as hypothesized, differentially predicted aspects of Internet-specific reading motivation and engagement. Taken together, these results provide evidence for the construct validity of the ISEJ and lay the foundation for further validation of the instrument.

Because the current investigation was limited to a sample of Norwegian pre-service teachers and the content domain of education, further research using this instrument should involve other student populations and domains and, preferably, be conducted across cultural contexts. Accordingly, follow-up research using the ISEJ is currently being conducted with German undergraduates who report on their Internet-specific justification beliefs in the content domain of natural science. Moreover, it seems important to compare students' scores on the dimensions of justification by authority, personal justification, and justification by multiple sources with what they actually do when using the Internet to learn about a particular topic, with the latter captured by means of online methodologies such as reading times, eye tracking, or verbal protocols. For example, using verbal protocol analysis (Ericsson \& Simon, 1993), Greene and colleagues (Greene, Copeland, Deekens, \& Yu, 2018; Greene, Yu, \& Copeland, 2014) investigated students' thinking about knowledge and knowing while studying a scientific topic on the Internet. These authors found that students justified knowledge claims through the testimony of an external authority, reliance on their own perception, memory, or rationality, and the existence of consistency across claims and sources, with these categories essentially representing the three justification constructs underlying our participants' scores on the ISEJ. To what extent students' scores on the three dimensions of 
the ISEJ reliably predict their application of corresponding justification procedures when actually learning within Internet technologies is not answered by the current study, however, and we consider it an important next step in research on the instrument to address this question.

Future research using this instrument may also employ cluster analysis to investigate whether particular profiles of Internet-specific justification beliefs are more or less adaptive in the context of learning subject matter on the Internet. For example, some online learning tasks may require an interactive coordination of different epistemic processes (Cho, Woodward, \& Li, in press), which may be reflected in students' epistemic justification profiles based on their ISEJ scores. It is also conceivable that different profiles will be more or less adaptive dependent on the familiarity of the topic. It is possible, for example, that a profile characterized by more emphasis on justification by authority and justification by multiple sources and less emphasis on personal justification is more important when the topic is less familiar. Conversely, when the topic is more familiar, learners can rely more on personal justification and less on justification by authority and justification by multiple sources (cf., McCrudden, Stenseth, Bråten, \& Strøms $\varnothing, 2016)$. Likewise, what is an adaptive epistemic justification profile may vary with the degree of conflict between claims, with a strong emphasis on justification by multiple sources being particularly important when learning about a controversial issue from online sources that present different views on the issue (Cho \& Afflerbach, 2017; Wineburg, 1991).

Beyond suggesting exciting avenues for future research, the theoretical significance of the current study lies in promoting understanding of the constructs that explain how students think about epistemic justification of claims and information encountered on the Internet. An open theoretical question is, however, whether the thinking about epistemic justification that is reported on the ISEJ is best characterized as beliefs, as we did in the current study, or 
whether it rather should be characterized as forms of self-reported epistemic validation strategies (Richter \& Maier, 2017; Richter \& Schmid, 2010). This question parallels the issue of how to distinguish between epistemic beliefs and epistemic cognition, recently highlighted by Sinatra (2016). In accordance with her clarification, we have considered responses on the ISEJ to reflect what students believe about epistemic justification on the Internet rather than (reports of) epistemic strategies or processes that unfold during Internet use. Hopefully, future research will also clarify to what extent these beliefs are brought to bear on Internet-based learning tasks that require strategic processing to justify or validate knowledge claims.

Finally, this study has educational as well as theoretical implications. Educating critical thinkers is a 21 st century priority, and students' beliefs about epistemic justification on the Internet presumably play an important role in this regard (Greene \& Yu, 2015). It is therefore highly pertinent to assess such beliefs among students at different educational levels and to try to change them through instructional interventions when deemed necessary. Regarding the latter, Kammerer et al. (2015) recently showed that a brief intervention targeting source evaluation strengthened participants' Internet-specific beliefs in justification by multiple sources, and Ferguson et al. (2013) found that having students work with conflicting texts on an unfamiliar controversial issue weakened their beliefs in personal justification and strengthened their beliefs in justification by multiple sources. Hopefully, the ISEJ will become a functional tool for assessing students' Internet-specific epistemic beliefs that also can be used to evaluate the effects of interventions aiming to foster adaptive beliefs in the service of critical thinking. As this study suggests, such interventions targeting Internetspecific epistemic beliefs may also affect students' motivation and engagement when reading about academic issues on the Internet, with strengthening beliefs in justification by multiple sources, in particular, having the potential to increase perceived competence and dedication 
and decrease avoidance, Further experimental work is needed to bolster this idea based on correlational data, however. 


\section{References}

Bentler, P.M. (1990). Comparative fit indexes in structural models. Psychological Bulletin, 107, 238-246. http://dx.doi.org/10.1037/0033-2909.107.2.238

Bentler, P.M., \& Bonett, D.G. (1980). Significance tests and goodness of fit in the analysis of covariance structures. Psychological Bulletin, 88, 588-606. http://dx.doi.org/10.1037/0033-2909.88.3.588

Braasch, J.L.G., Bråten, I., Britt, M.A., Steffens, B., \& Strømsø, H.I. (2014). Sensitivity to inaccurate argumentation in health news articles: Potential contributions of readers' topic and epistemic beliefs. In D.N. Rapp \& J.L.G. Braasch (Eds.), Processing inaccurate information: Theoretical and applied perspectives from cognitive science and the educational sciences (pp. 117-137). Cambridge, MA: The MIT Press.

Brandmo, C., \& Bråten, I. (2018). Investigating relations between beliefs about justification for knowing, interest, and knowledge across two socio-scientific topics. Learning and Individual Differences, 62, 89-97. https://doi.org/10.1016/j.lindif.2018.01.010

Bråten, I. (2011). Personal epistemology in education. In V.G. Aukrust (Ed.), Learning and cognition in education (pp. 52-58). Oxford: Elsevier.

Bråten, I., \& Braasch, J.L.G. (2017). Key issues in research on students' critical reading and learning in the 21 st century information society. In C. $\mathrm{Ng} \& \mathrm{~B}$. Bartlett (Eds.), Improving reading and reading engagement in the 21 st century: International research and innovations. (pp. 77-98). Singapore: Springer.

Bråten, I., Anmarkrud, Ø., Brandmo, C., \& Strømsø, H.I. (2014). Developing and testing a model of direct and indirect relationships between individual differences, processing, and multiple-text comprehension. Learning and Instruction, 30, 9-24.

https://doi.org/10.1016/j.learninstruc.2013.11.002

Bråten, I., \& Ferguson, L.E. (2014). Investigating cognitive capacity, personality, and 
epistemic beliefs in relation to science achievement. Learning and Individual Differences, 36, 124-130. https://doi.org/10.1016/j.lindif.2014.10.003

Bråten, I., Ferguson, L.E., Anmarkrud, Ø., Strømsø, H.I., \& Brandmo, C. (2014). Modeling relations between students' justification for knowing beliefs in science, motivation for understanding what they read in science, and science achievement. International Journal of Educational Research, 66, 1-12. https://doi.org/10.1016/j.ijer.2014.01.004

Bråten, I., Ferguson, L.E., Strøms $\varnothing$, H.I., \& Anmarkrud, Ø. (2013). Justification beliefs and multiple-documents comprehension. European Journal of Psychology of Education, 28, 879-902. https://doi.org/10.1007/s10212-012-0145-2

Bråten, I., Ferguson, L.E., Strømsø, H.I., \& Anmarkrud, Ø. (2014). Students working with multiple conflicting documents on a scientific issue: Relations between epistemic cognition while reading and sourcing and argumentation in essays. British Journal of Educational Psychology, 84, 58-85. doi:10.1111/bjep.12005

Bråten, I., Gil, L., Strømsø, H.I., \& Vidal-Abarca, E. (2009). Personal epistemology across cultures: Exploring Norwegian and Spanish university students' epistemic beliefs about climate change. Social Psychology of Education, 12, 529-560. https://doi.org/10.1007/s11218-009-9097-z

Bråten, I., Strøms $\varnothing$, H.I., \& Ferguson, L.E. (2016). The role of epistemic beliefs in the comprehension of single and multiple texts. In P. Afflerbach (Ed.), Handbook of individual differences in reading: Reader, text, and context (pp. 67-79). New York: Routledge.

Bråten, I., Strømsø, H.I., \& Samuelstuen, M.S. (2005). The relationship between Internetspecific epistemological beliefs and learning within Internet technologies. Journal of Educational Computing Research, 33, 141-171. https://doi.org/10.2190/E763-X0LN6NMF-CB86 
Brown, T.A. (2015). Confirmatory factor analysis for applied research (2nd ed.). New York: Guilford.

Campbell, D.T., \& Fiske, D.W. (1959). Convergent and discriminant validation by the multitrait-multimethod matrix. Psychological Bulletin, 56, 81-105. http://psycnet.apa.org/doi/10.1037/h0046016

Cheng, K.-H., Liang, J.-C., \& Tsai, C.-C. (2013). The role of Internet-specific epistemic beliefs and self-regulation in high school students' online academic help seeking: A structural equation modeling analysis. Journal of Educational Computing Research, 48, 469-489. https://doi.org/10.2190/EC.48.4.d

Chinn, C.A., Buckland, L.A., \& Samarapungavan, A. (2011). Expanding the dimensions of epistemic cognition: Arguments from philosophy and psychology. Educational Psychologist, 46, 141-167. https://doi.org/10.1080/00461520.2011.587722

Chiu, Y.-L., Liang, J.-C., \& Tsai., C.-C. (2013). Internet-specific beliefs and self-regulated learning in online academic information searching. Metacognition and Learning, 8, 235-260. https://doi.org/10.1007/s11409-013-9103-x

Chiu, Y.-L., Liang, J.-C., \& Tsai., C.-C. (2016). Exploring the roles of education and Internet search experiences in students' Internet-specific epistemic beliefs. Computers in Human Behavior, 62, 286-291. https://doi.org/10.1016/j.chb.2016.03.091

Chiu, Y.-L., Tsai., C.-C., \& Liang, J.-C. (2015). Testing measurement invariance and latent mean differences across gender groups in college students' Internet-specific epistemic beliefs. Australasian Journal of Educational Technology, 31, 486-499. https://doi.org/10.14742/ajet.1437

Cho, B.-Y., \& Afflerbach, P. (2017). An evolving perspective of constructively responsive 
reading comprehension strategies in multilayered digital text environments. In S.E. Israel (Ed.), Handbook of research on reading comprehension (2nd ed., pp. 109-134). New York: Guilford.

Cho, B.-Y., Woodward, L., \& Li, D. (in press). Epistemic processing when adolescents read online: A verbal protocol analysis of more and less successful online readers. Reading Research Quarterly. http://dx.doi.org/10.1002/rrq.190

Cronbach, L.J. (1990). Essentials of psychological testing (5th ed.). Reading, MA: AddisonWesley.

Cronbach, L.J., \& Meehl, P. (1955). Construct validity in psychological tests. Psychological Bulletin, 52, 281-302. http://psycnet.apa.org/doi/10.1037/h0040957

Ericsson, K.A., \& Simon, H.A. (1993). Protocol analysis: Verbal reports as data (rev. ed.). Cambridge, MA: MIT Press

Ferguson, L.E., \& Bråten, I. (2013). Student profiles of knowledge and epistemic beliefs: Changes and relations to multiple-text comprehension. Learning and Instruction, 25, 49-61. https://doi.org/10.1016/j.learninstruc.2012.11.003

Ferguson, L.E., Bråten, I., \& Strømsø, H.I. (2012). Epistemic cognition when students read multiple documents containing conflicting scientific evidence: A think-aloud study. Learning and Instruction, 22, 103-120. https://doi.org/10.1016/j.learninstruc.2011.08.002

Ferguson, L.E., Bråten, I., Strømsø, H.I., \& Anmarkrud, Ø. (2013). Epistemic beliefs and comprehension in the context of reading multiple documents: Examining the role of conflict. International Journal of Educational Research, 62, 100-114. https://doi.org/10.1016/j.ijer.2013.07.001 
Graham, J.M. (2006). Congeneric and (essentially) tau-equivalent estimates of score reliability. Educational and Psychological Measurement, 66, 930-944. https://doi.org/10.1177/0013164406288165

Greene, J.A., Azevedo, R., \& Torney-Purta, J. (2008). Modeling epistemic and ontological cognition: Philosophical perspectives and methodological directions. Educational Psychologist, 43, 142-160. https://doi.org/10.1080/00461520802178458

Greene, J.A., Copeland, D.Z., Deekens, V.M., \& Yu, S.B. (2018). Beyond knowledge: Examining digital literacy's role in the acquisition of understanding in science. Computers \& Education, 117, 141-159. https://doi.org/10.1016/j.compedu.2017.10.003

Greene, J.A., Torney-Purta, J., \& Azevedo, R. (2010). Empirical evidence regarding relations among a model of epistemic and ontological cognition, academic performance, and educational level. Journal of Educational Psychology, 102, 234-255. http://psycnet.apa.org/doi/10.1037/a0017998

Greene, J.A., \& Yu, S.B. (2015). Educating critical thinkers: The role of epistemic cognition. Policy Insights from the Behavioral and Brain Sciences, 3, 45-53. https://doi.org/10.1177/2372732215622223

Greene, J.A., Yu, S.B., \& Copeland, D.Z. (2014). Measuring critical components of digital literacy and their relationships with learning. Computers \& Education, 76, 55-69. https://doi.org/10.1016/j.compedu.2014.03.008

Guthrie, J.T., \& Klauda, S.L. (2014). Effects of classroom practices on reading comprehension, engagement, and motivations for adolescents. Reading Research Quarterly, 49, 387-416. http://dx.doi.org/10.1002/rrq.81 
Hofer, B.K. (2002). Personal epistemology as a psychological an educational construct: An introduction. In B.K. Hofer \& P.R. Pintrich (Eds.), Personal epistemology: The psychology of beliefs about knowledge and knowing (pp. 3-14). Mahwah, NJ: Erlbaum.

Hofer, B.K., \& Bendixen, L.D. (2012). Personal epistemology: Theory, research, and future directions. In K.R. Harris, S. Graham, \& T. Urdan (Eds.), APA Educational Psychology Handbook: Vol. 1. Theories, constructs, and critical issues (pp. 227-256). Washington, DC: American Psychological Association.

Hofer, B.K., \& Pintrich, P.R. (1997). The development of epistemological theories: Beliefs about knowledge and knowing and their relation to learning. Review of Educational Research, 67, 88-140. https://doi.org/10.3102/00346543067001088

Hu, L.T., \& Bentler, P.M. (1998). Fit indices in covariance structure modeling: Sensitivity to underparameterized model misspecification. Psychological Methods, 3, 424-453. http://psycnet.apa.org/doi/10.1037/1082-989X.3.4.424

Hu, L.T., \& Bentler, P.M. (1999). Cutoff criteria for fit indexes in covariance structure analysis: Conventional criteria versus new alternatives. Structural Equation Modeling, 6, 1-55. https://doi.org/10.1080/10705519909540118

Kammerer, Y., Amann, D.G., \& Gerjets, P. (2015). When adults without university education search the Internet for health information: The roles of Internet-specific epistemic beliefs and a source evaluation intervention. Computers in Human Behavior, 48, $297-$ 309. https://doi.org/10.1016/j.chb.2015.01.045

Kammerer, Y., Bråten, I., Gerjets, P., \& Strømsø, H.I. (2013). The role of Internet-specific epistemic beliefs in laypersons' source evaluations and decisions during Web search on a medical issue. Computers in Human Behavior, 29, 1193-1203. https://doi.org/10.1016/j.chb.2012.10.012

Kammerer, Y., \& Gerjets, P. (2012). Effects of search interface and Internet-specific epistemic 
beliefs on source evaluations during Web search for medical information: An eyetracking study. Behaviour \& Information Technology, 31, 83-97. https://doi.org/10.1080/0144929X.2011.599040

Karaoglan Yilmaz, F.G., \& Cakmak, E.K. (2016). Internet-specific epistemological beliefs and online information searching strategies of pre-service teachers: Gender and department differences. Participatory Educational Research, 3, 63-80. doi:10.17275/per.16.10.3.2

Karimi, M.N. (2014). EFL students' grammar achievement in a hypermedia context: Exploring the role of Internet-specific personal epistemology. System, 42, 1-11. https://doi.org/10.1016/j.system.2013.10.017

Kendeou, P., Braasch, J.L.G., \& Bråten, I. (2016). Optimizing conditions for learning: Situating refutations in epistemic cognition. Journal of Experimental Education, 84, 245-263. https://doi.org/10.1080/00220973.2015.1027806

Kerlinger, F.N., \& Lee, H.B. (2000). Foundations of behavioral research (4th ed.). Forth Worth, TX: Harcourt College Publishers.

Kline, R.B. (2005). Principles and practice of structural equation modeling (2nd ed.). New York: Guilford.

Knight, S., Rienties, B., Littleton, K., Mitsui, M., \& Tempelaar, D. (2017a). The relationship of (perceived) epistemic cognition to interaction with resources on the Internet. Computers in Human Behavior, 73, 507-518. https://doi.org/10.1016/j.chb.2017.04.014

Knight, S., Rienties, B., Littleton, K., Tempelaar, D., Mitsui, M., \& Shah, C. (2017b). The orchestration of a collaborative information seeking learning task. Information Retrieval Journal, 20, 480-505. https://doi.org/10.1007/s10791-017-9304-Z

Lankes, R.D. (2008). Trusting the Internet: New approaches to credibility tools. In M.J. Metzger \& A.J. Flanagin (Eds.), Digital media, youth, and credibility (pp. 101-121). Combridge, MA: The MIT Press. 
Lee, W.-C., Chiu, Y.-L., Liang, J.-C., \& Tsai, C.-C. (2014). Exploring the structural relationships between high school students' Internet-specific epistemic beliefs and their utilization of online academic help seeking. Computers in Human Behavior, 36, 391-400. https://doi.org/10.1016/j.chb.2014.03.069

Lucassen, T., Muilwijk, R., Noordzij, M.L., \& Schraagen, J.M. (2013). Topic familiarity and information skills in online credibility evaluation. Journal of the American Society for Information Science and Technology, 64, 254-264.

Marsh, H.W., Hau, K.T., \& Wen, Z. (2004). In search of golden rules: Comment on hypothesis testing approaches to setting cutoff values for fit indexes and dangers in overgeneralizing Hu and Bentler's (1999) findings. Structural Equation Modeling, 11, 320-341. https://doi.org/10.1207/s15328007sem1103_2

Mason, L., \& Florit, E. (2018). Complementary methods for assessing online processing of multiple sources. In J.L.G. Braasch, I. Bråten, \& M.T. McCrudden (Eds.), Handbook of multiple source use (pp. 425-446). New Yok: Routledge.

McCrudden, M.T., Stenseth, T., Bråten, I., \& Strømsø, H.I. (2016). The effects of author expertise and content relevance on document selection: A mixed methods study. Journal of Educational Psychology, 108, 147-162. http://psycnet.apa.org/doi/10.1037/edu0000057

Muis, K.R., Bendixen, L.D., \& Haerle, F.C. (2006). Domain-generality and domainspecificity in personal epistemology research: Philosophical and empirical reflections in the development of a theoretical framework. Educational Psychology Review, 18, 354. https://doi.org/10.1007/s10648-006-9003-6

Muthén, L.K., \& Muthén, B. (2012). Mplus user's guide Version 7. Los Angeles, CA: Muthén \& Muthén. 
Richter, T., \& Maier, J. (2017). Comprehension of multiple documents with conflicting information: A two-step model of validation. Educational Psychologist, 52, 148-166. https://doi.org/10.1080/00461520.2017.1322968

Richter, T., \& Schmid, S. (2010). Epistemological beliefs and epistemic strategies in selfregulated learning. Metacognition and Learning, 5, 47-65. https://doi.org/10.1007/s11409-009-9038-4

Sandoval, W.A., Greene, J.A., \& Bråten, I. (2016). Understanding and promoting thinking about knowledge: Origins, issues, and future directions of research on epistemic cognition. Review of Research in Education, 40, 457-496.

https://doi.org/10.3102/0091732X16669319

Schermelleh-Engel, K., Moosbrugger, H., \& Müller, H. (2003). Evaluating the fit of structural equation models: Tests of significance and descriptive goodness-of-fit measures. Methods of Psychological Research Online, 8, 23-74. http://www.mpr-online.de

Sinatra, G.M. (2016). Thoughts on knowledge about thinking about knowledge. In J.A.

Greene, W.A. Sandoval, \& I. Bråten (Eds.), Handbook of epistemic cognition (pp. 479-491). New York: Routledge.

Strøms $\varnothing$, H.I., \& Bråten, I. (2010). The role of personal epistemology in self-regulation of Internet-based learning. Metacognition and Learning, 5, 91-111. https://doi.org/10.1007/s11409-009-9043-7

Strøms $\varnothing$, H.I., Bråten, I., Anmarkrud, Ø., \& Ferguson, L.E. (2016). Beliefs about justification for knowing when ethnic-majority and ethnic-minority students read multiple conflicting documents. Educational Psychology, 36, 638-657. https://doi.org/10.1080/01443410.2014.920080

Strøms $\varnothing$, H.I., \& Kammerer, Y. (2016). Epistemic cognition and reading for understanding in the Internet age. In J.A. Greene, W.A. Sandoval, \& I. Bråten (Eds.), Handbook of 
epistemic cognition (pp. 230-246). New York: Routledge.

Sussman, S.W., \& Siegal, W.S. (2003). Informational influence in organizations: An integrated approach to knowledge adoption. Information Systems Research, 14, 47-65.

Trevors, G.J., Kendeou, P., Bråten, I., \& Braasch, J.L.G. (2017). Adolescents’ epistemic profiles in the service of knowledge revision. Contemporary Educational Psychology, 49, 107-120. https://doi.org/10.1016/j.cedpsych.2017.01.005

Wineburg, S.S. (1991). Historical problem solving: A study of the cognitive processes used in the evaluation of documentary and pictorial evidence. Journal of Educational Psychology, 83, 73-87. http://psycnet.apa.org/doi/10.1037/0022-0663.83.1.73 
Table 1

Descriptive Statistics, Factor Loadings, and Validity and Reliability Information for the Internet-Specific Epistemic Justification Inventory

\begin{tabular}{|c|c|c|c|c|c|c|c|c|c|}
\hline Factor & Item\# & Loading & Mean & $S D$ & Skewness & Kurtosis & FDS & $\alpha$ & $\rho$ \\
\hline $\begin{array}{l}\text { Personal } \\
\text { justification }\end{array}$ & $\begin{array}{l}1 \\
4 \\
7 \\
10\end{array}$ & $\begin{array}{l}.68 \\
.73 \\
.73 \\
.89\end{array}$ & $\begin{array}{l}7.41 \\
6.81 \\
8.03 \\
7.42\end{array}$ & $\begin{array}{l}2.09 \\
2.32 \\
1.93 \\
2.08\end{array}$ & $\begin{array}{l}-0.54 \\
-0.55 \\
-1.03 \\
-0.70\end{array}$ & $\begin{array}{r}-0.31 \\
-0.37 \\
0.60 \\
0.00\end{array}$ & .94 & .84 & .80 \\
\hline $\begin{array}{l}\text { Justification by } \\
\text { multiple sources }\end{array}$ & $\begin{array}{l}2 \\
5 \\
8 \\
11\end{array}$ & $\begin{array}{l}.79 \\
.88 \\
.91 \\
.90\end{array}$ & $\begin{array}{l}6.46 \\
6.25 \\
6.48 \\
6.67\end{array}$ & $\begin{array}{l}2.71 \\
2.66 \\
2.55 \\
2.47\end{array}$ & $\begin{array}{l}-0.31 \\
-0.29 \\
-0.38 \\
-0.42\end{array}$ & $\begin{array}{r}1.00 \\
-0.92 \\
-0.77 \\
-0.72\end{array}$ & .97 & .92 & .92 \\
\hline $\begin{array}{l}\text { Justification by } \\
\text { authority }\end{array}$ & $\begin{array}{l}3 \\
6 \\
9 \\
12\end{array}$ & $\begin{array}{l}.81 \\
.78 \\
.93 \\
.91\end{array}$ & $\begin{array}{l}7.43 \\
6.84 \\
7.03 \\
6.98\end{array}$ & $\begin{array}{l}2.49 \\
2.50 \\
2.54 \\
2.50\end{array}$ & $\begin{array}{l}-0.90 \\
-0.58 \\
-0.76 \\
-0.71\end{array}$ & $\begin{array}{l}-0.12 \\
-0.65 \\
-0.34 \\
-0.40\end{array}$ & .97 & .92 & .92 \\
\hline
\end{tabular}

Note. Loadings are standardized, $S D=$ standard deviation, FDS = factor determinacy score,

$\alpha=$ Cronbach's alpha, $\rho=$ reliability of the latent factor. 
Table 2

Intercorrelations, Means, and Standard Deviations for All Latent Variables

\begin{tabular}{|c|c|c|c|c|c|c|c|c|}
\hline & Variable & 1 & 2 & 3 & 4 & 5 & 6 & 7 \\
\hline 1 & Personal justification & - & & & & & & \\
\hline 2 & Justification by multiple sources & $.58 * * *$ & - & & & & & \\
\hline 3 & Justification by authority & $.56 * * *$ & $.67 * * *$ & - & & & & \\
\hline 4 & Perceived competence & $.20 * * *$ & $.30 * * *$ & $.12 *$ & - & & & \\
\hline 5 & Dedication & $.19 * * *$ & $.23 * * *$ & $.17 * *$ & $.69 * * *$ & - & & \\
\hline 6 & Perceived difficulty & $-.27 * * *$ & $-.16 * *$ & $-.21 * * *$ & .00 & .04 & - & \\
\hline \multirow[t]{3}{*}{7} & Avoidance & -.10 & $-.20 * * *$ & $-.13 *$ & $-.65 * * *$ & $-.56 * * *$ & $.31 * * *$ & - \\
\hline & Mean & 7.42 & 6.47 & 7.06 & 5.61 & 3.32 & 3.05 & 3.92 \\
\hline & $S D$ & 1.74 & 2.35 & 2.25 & 2.02 & 1.68 & 1.54 & 2.17 \\
\hline
\end{tabular}

${ }^{*} p<.05, * * p<.01, * * * p<.001$. 
Figure captions

Figure 1 . The hypothesized model. $+=$ positive prediction, $-=$ negative prediction,$+/-=$ valence not prespecified.

Figure 2. The resulting model for justification constructs and reading motivation and engagement constructs. $* p<.05, * * p<.01, * * * p<.001$. 


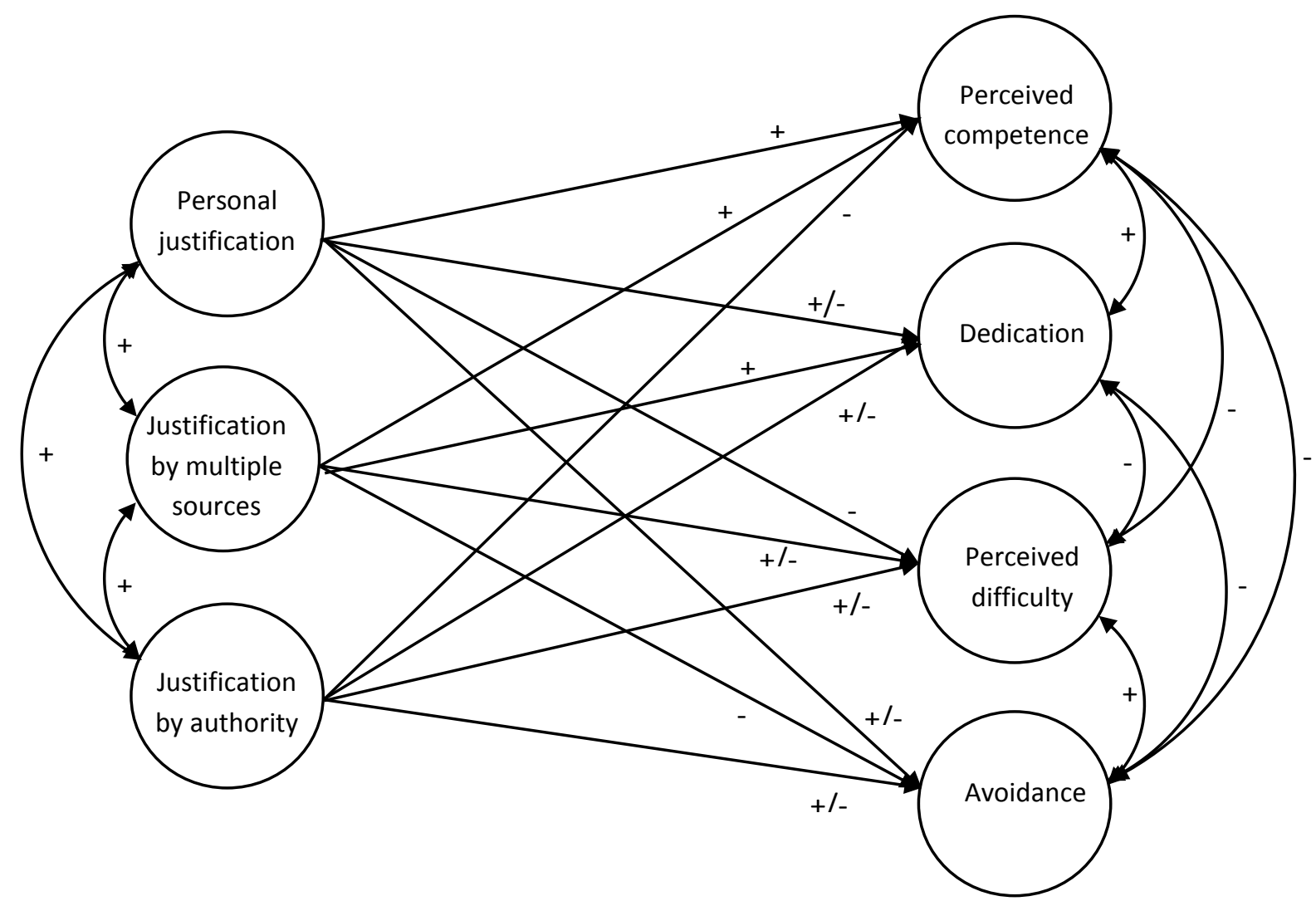

Figure 1 


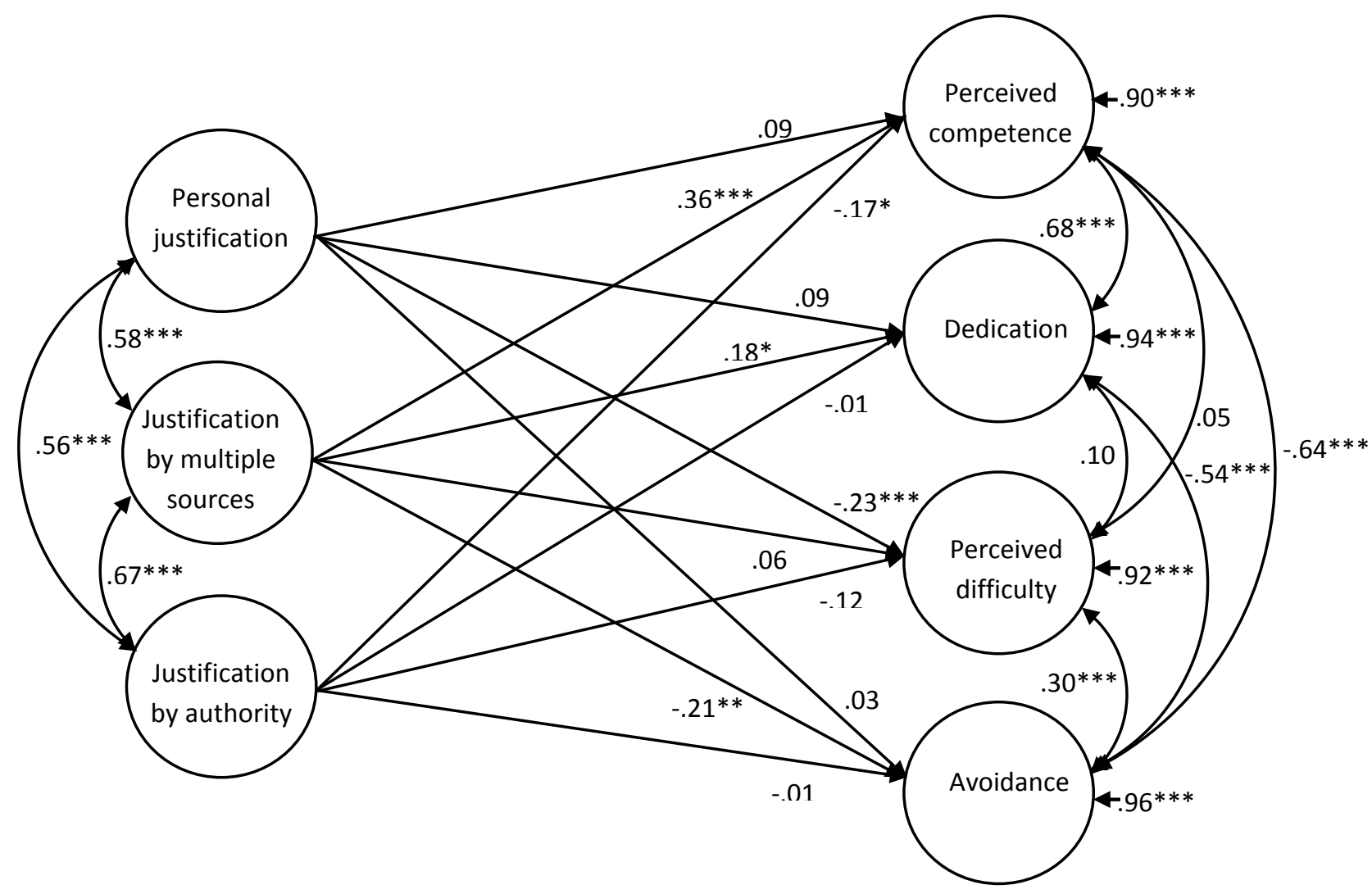

Figure 2 
Appendix A

Items on the Internet-Specific Epistemic Justification Inventory

Item \# $\quad$ Item wording

Personal justification

1. When I find information about an educational topic on the Internet, I evaluate whether this information is consistent with my own understanding of the topic.

4. To check whether information about an educational topic I find on the Internet is reliable, I evaluate it in relation to my own knowledge of this topic.

7. I evaluate whether information I find about an educational topic on the Internet seems logical.

10. When I read about an educational topic on the Internet, I evaluate whether this information is consistent with what I already know about this topic.

\section{Justification by multiple sources}

2. I evaluate claims I find about an educational topic on the Internet by checking several information sources on the same topic.

5. When I read something about an educational topic on the Internet, I compare several websites that deal with this topic.

8. To evaluate whether information I find on the Internet about an educational topic is reliable, I check whether it is consistent with information on other websites.

11. To determine whether information I find about an educational topic on the Internet is trustworthy, I compare information from multiple sources.

\section{Justification by authority}

3. When I read something about an educational topic on the Internet, I evaluate whether this information is written by an expert.

6. To determine whether information I find about an educational topic on the Internet is trustworthy, I evaluate whether the author has sufficient knowledge of the topic.

9. When I find information about an educational topic on the Internet, I check whether it comes from an expert source.

12. To evaluate whether information I find about an educational topic on the Internet is reliable, I try to determine whether it is written by a person with a high level of competence in the area. 
Appendix B

Internet-Specific Reading Motivation and Engagement Measures

\section{Perceived competence}

I figure out the meaning of central academic concepts by reading about educational topics on the Internet.

I obtain key information on educational topics by reading about them on the Internet.

I find solutions to academic issues by reading about educational topics on the Internet.

\section{Perceived difficulty}

What I read on the Internet about educational topics is far too difficult for me.

I have difficulty explaining what I read on the Internet about educational topics to other students.

What I read about educational topics on the Internet only confuses me.

\section{Dedication}

I make sure I set aside enough time to read about educational topics on the Internet.

I spend more time and effort on reading about educational topics on the Internet than other students.

I put a lot of effort into reading about educational topics on the Internet.

\section{Avoidance}

When I read about educational topics on the Internet, I feel that I'm wasting my time.

I read as little as possible about educational topics on the Internet.

I avoid reading anything about educational topics on the Internet. 